\title{
Reply: the role of ultrasound in pediatric salivary gland imaging
}

\author{
Zachary T. Boyd • Lisa H. Lowe • Asha R. Goud • \\ Lei Shao
}

Received: 9 December 2009 / Accepted: 10 December 2009/Published online: 24 February 2010

(C) Springer-Verlag 2010

Sir,

We would like to thank Sodhi et al. [1] for their comments regarding our pictorial essay titled "Pediatric salivary gland imaging" [2]. We agree that CT imaging in children should be used quite judiciously in order to limit radiation exposure. We included CT images of infantile hemangiomas and parotitis for educational purposes and did not mean to imply that this was the recommended initial modality for imaging.
We appreciate the comments regarding sialoadenosis and agree with the description given by Sodhi et al. [1].

\section{References}

1. Sodhi KS, Saxena AK, Khandelwal N (2010) Pediatric salivary gland imaging: comments on pictorial essay by Boyd et al. Pediatr Radiol 40. doi 10.1007/s00247-009-1509-x

2. Boyd ZT, Goud AR, Lowe LH et al (2009) Pediatric salivary gland imaging. Pediatr Radiol 39:710-722

Z. T. Boyd $(\bowtie)$

University of Missouri-Kansas City Department of Medicine,

2411 Holmes St.,

Kansas City, MO 64108, USA

e-mail: Zachary.boyd@gmail.com

L. H. Lowe

Department of Radiology, Children's Mercy Hospitals and Clinics and the University of Missouri-Kansas City,

Kansas City, MO, USA

\section{A. R. Goud}

Department of Radiology,

University of California Irvine Medical Center,

Orange, CA, USA

L. Shao

Department of Pathology, Children's Mercy Hospitals and Clinics and the University of Missouri-Kansas City,

Kansas City, MO, USA 